\title{
Blood tests in the management of Helicobacter pylori infection
}

D Vaira, J Holton, M Menegatti, F Landi, C Ricci, A Ali', L Gatta, S Farinelli, C Acciardi, B Massardi, M Miglioli and the Italian Helicobacter pylori Study Group

\begin{abstract}
Summary
There are three main types of blood test available for the management of Helicobacter pylori infection: those that detect an antibody response; tests of the pathophysiological state of the stomach; and those that indicate an active infection. Enzyme linked immunosorbent assay (ELISA) based kits are the most numerous of the commercially available tests. Originally the kits used crude antigen preparations but many of the newer kits use a more purified antigen preparation giving increased specificity but a lower sensitivity. The sensitivity, specificity, and predictive values of the tests can also be affected by the population under test and coexistent disease in the patients. Near patient test kits are based on either latex agglutination or immunochromatography. Generally, they have low sensitivities compared with laboratory tests. Commerical western blotting kits have also been developed and are used to detect the presence of specific virulence markers. The exact role of serology in the management of Helicobacter infection has still to be defined, although there is evidence that, used as a screening procedure, it can reduce endoscopy cost and workload. Gastrin and pepsinogen blood concentrations may provide valuable information on the pathophysiological state of the stomach-for example, the presence of inflammation or gastric atrophy. A combination of serology and serum concentrations of gastrin and pepsinogen may be used effectively to detect serious gastroduodenal disease in patients.
\end{abstract}

\section{Introduction}

Helicobacter pylori has been linked with an increasing number of conditions since its first suggested association with gastritis, now well established. Knowledge about the pathogenesis of peptic ulcer disease (PUD) has been revolutionised by the isolation of $H$ pylori, and, as a natural consequence of this, the management of PUD has completely changed from one of primarily acid suppression to one of primarily bacterial eradication. The causal association between colonisation by $H$ pylori, PUD, and gastric cancer places $H$ pylori as an important human pathogen. The link between colonisation by $H$ pylori and the risk of developing various forms of gastric neoplasm raises the exciting prospect of reducing the risk of neoplasm development by some form of eradication therapy at a population or even individual level. A natural corollary of this is the requirement of an effective screening procedure to determine colonisation status. In addition, the possible association between the widespread patho- physiological effects of chronic inflammation in the stomach and the risk of ischaemic heart disease, growth retardation, and gall stones also suggests the need for cost-effective management protocols.

Generally, there are a number of factors that must be included in an effective protocol for all aspects of disease management. For example, there should be an accurate diagnostic procedure at an individual level and a cost-effective population screening procedure. Also, the ability to determine prognostic indicators may influence management of the disease and there should be an effective follow up protocol to establish efficacy of treatment and recurrence of disease. More specifically, with respect to determining colonisation by $\mathrm{H}$ pylori and associated disease, blood tests are one of the two non-invasive techniques available; the other is the urea breath test (UBT).

\section{Antibody tests for $H$ pylori}

EVALUATION OF ANTIGEN

Several different antigen preparations have been tested. Initially, crude sonicates were used, and, although the sensitivity of the test was high, the specificity was relatively low compared with other diagnostic tests such as culture or histology, because of false positives caused by non-specific cross reactions with other organisms - for example, Campylobacter sp.

Comparison of a whole cell preparation and an acid-glycine extract ${ }^{1}$ showed enrichment of some immunodiagnostic antigens in the acidglycine extract (the 54 and $69 \mathrm{kDa}$ proteins) but complete loss of others (the 29 and $120 \mathrm{kDa}$ proteins). Further, although the intention was to reduce non-specific cross reactions, they were still detectable when assessed by western blotting. A more extensive study ${ }^{2}$ compared crude sonicates with ultracentrifuged whole cell sonicates and acid-glycine extracts and antigen fractions separated by sodium dodecyl sulphatepolyacrylamide gel electrophoresis. The greatest discrimination between $H$ pylori positive and negative sera was found with high molecular mass fraction antigens, but whole cell sonicates were better than acid-glycine extracted antigens. A further comparison of four different antigen preparations (crude sonicate, acid-glycine extract, acid-glycine extract of a flagellate organism, and urease enriched fraction) showed the crude sonicate to have the highest sensitivity but the lowest specificity. ${ }^{3}$ A study using more purified antigen prepared by fast protein liquid chromatography (FPLC) or monoclonal antibody capture generally showed lower sensitivities of the purified antigens compared with an acid-glycine extract, with specificities of $100 \%$ 
Table 1 Sensitivity and specificity of the different antigens

\begin{tabular}{lll}
\hline Antigen preparation & Sensitivity (\%) & Specificity (\%) \\
\hline Crude sonicate & $94-100$ & $60-100$ \\
Ultracentrifuged sonicate & $84-97$ & $95-100$ \\
Surface antigen & 82 & 92 \\
Acid-glycine extract & $82-95$ & $83-98$ \\
Acid-glycine extract & 89 & 96 \\
Urease preparation & $81-97$ & $89-90$ \\
120 kDa protein (CagA) & $84-96$ & $92-98$ \\
Recombinant cagA & 96 & 96 \\
CagA + ultracentrifuged sonicate & 97 & 100 \\
CagA + acid-glycine extract & 97 & 100 \\
FPLC purified urease & 91 & 91 \\
FPLC purified flagelia & 78 & 93 \\
MAb purified urease & 83 &
\end{tabular}

Prepared from references $1-11$

*Acid-glycine extract from an aflagellate organism.

FPLC, fast protein liquid chromatography; MAb, monoclonal antibody.

for most of the fractions. ${ }^{4}$ In one serological assay using the $120 \mathrm{kDa}(\mathrm{CagA})$ protein purified by size exclusion chromatography ${ }^{5}$ and compared with a whole cell preparation, the sensitivities and specificities were 96 and $100 \%$ and 92 and $60 \%$ respectively for the whole cell preparation. Several other studies have also compared different antigen preparation as the basis for serological tests. ${ }^{6-11}$

These results show, not unexpectedly, that there is a trade off with antigen purification between loss of sensitivity and increased specificity. Immunoblots have shown qualitative and quantitative differences in the pattern of response in patients, and this emphasises that the type of strain of $H$ pylori and the method of preparation of the antigens for serological tests may be critical to the test parameters. It is possible that a judicious combination of purified antigens may maximise

Table 2 Commercially produced serological assays for detection of Helicobacter pylori

\begin{tabular}{|c|c|c|c|}
\hline Kit & Kit & Test format & Manufacturer \\
\hline Helori-test & Helori-test & ELISA & Eurospital, Italy \\
\hline Pyloristat & Pylori ELISA II* & ELISA & BioWhittaker, USA \\
\hline Pyloriset & Pyloriset updata & ELISA & Orion, Finland \\
\hline Helico G & \multirow[t]{3}{*}{ Helico G2 } & ELISA & Shield, UK \\
\hline Premier HP & & ELISA & Meridian, USA \\
\hline Cobas Core & & ELISA & Roche, Switzerland \\
\hline Hel-p Test & \multirow[t]{2}{*}{ Hel-p Test II } & ELISA & Amrad, Australia \\
\hline Malakit & & ELISA & BioLab, Belgium \\
\hline GAP IgG & \multirow[t]{14}{*}{ GAP IgG2 } & ELISA & BioRad, USA \\
\hline Roche MTP & & ELISA & Roche, Switzerland \\
\hline Hp.G screen & & ELISA & Genesis, UK \\
\hline Microstar EIA & & ELISA & Kenstar, UK \\
\hline SIA Helicobacter & & ELISA & Sigma, USA \\
\hline HM-CAP EIA & & ELISA & Enteric Prod., USA \\
\hline Helisal EIA & & ELISA & Cortecs, UK \\
\hline H. pylori IgG & & ELISA & Dako, Denmark \\
\hline Autozyme & & ELISA & Cambridge LS, UK \\
\hline Pyloragen & & ELISA & Hycor, USA \\
\hline Enzygnost HP & & ELISA & Behring, UK \\
\hline Quidel HP EIA & & ELISA & Quidel, USA \\
\hline Enzywell HP EIA & & ELISA & Dresse Monteriggioni, Italy \\
\hline Color Vue Pylori & & ELISA & Seradyn, USA \\
\hline Pyloriset & Pyloriset Dry & LA & Orion, Finland \\
\hline Helisal RBT & Helisal One Step & IMC & Cortecs, UK \\
\hline FlexSureHPS & FlexSure WB† & IMC & SmithKline, USA \\
\hline Genesis Dot & & IMC & Genesis, UK \\
\hline QuickVueOnestep & & IMC & Quidel, USA \\
\hline Launch & & IMC & Meridian, USA \\
\hline \multicolumn{4}{|l|}{ Immunocard } \\
\hline Quadratech HEP & & IMC & VEDA, France \\
\hline CLOser & & IMC & Medical Inst.Corp, Switzerland \\
\hline HelicoBlot 2.0 & & WB & GeneLab, Singapore \\
\hline RIBA & & WB & Chiron USA \\
\hline
\end{tabular}

${ }^{\star}$ Pyloriset and Pylori ELISA II are no longer avaliable and have been replaced by $\mathrm{H}$ pylori IgG ELISA (Wample, USA). †FlexSure HP (SmithKline) is replaced by FlexPack (Abbott). Other kits are on the market - for example, Elagen (Immunogen International), $\mathrm{H}$ pylori IgG assay (Cozart) but little information is available.

ELISA, enzyme linked immunosorbent assay; LA, latex agglutination; IMC, immunochromatography; WB, western blotting. both sensitivity and specificity, and many second generation serological tests use purified or combinations of purified antigens. Table 1 shows the sensitivity and specificity of some antigen preparations and combinations.

\section{EVALUTATION OF COMMERCIALLY AVAILABLE} SEROLOGICAL ASSAYS

\section{ELISA kits}

Many publications have compared either single or many kits one against another ${ }^{12-18}$ in a defined population, usually patients with dyspepsia or PUD or symptomatic individuals. Table 2 lists the main commercial serological assays available for the detection of $H$ pylori. A comparison of the use of three kits for 76 patients using known culture positive cases showed comparable sensitivity and specificity of between 88 and $96 \%$ and 86 and $96 \%$ respectively. The inter- and intra-laboratory assay variation was low. The three kits used antigens of different purity: Pyloristat (urease enriched fractions), HelicoG (acid-glycine extract), Premier HP (high molecular mass cell associated proteins). ${ }^{19}$ In a further test on 95 dyspeptic patients, the Cobas Core anti- $H$ pylori immunoglobulin EIA-G, which uses an FPLC purified antigen, had a sensitivity and specificity of 94 and $98 \%$ respectively and was superior to the rapid urease test (RUT) (88 and $96 \%$ ) and culture (70 and 98\%) when compared with histology. ${ }^{20}$ A laboratory comparison of the three kits was carried out, which included modified Pyloriset EIA-G update kit and Malakit EIA-G ${ }^{21}$, on serum samples from 154 dyspeptic patients. Serological results were compared with those using culture/histology/ RUT as the "gold standard". The updated Pyloriset showed an improved sensitivity but reduced specificity compared with previous results for this kit from other studies on equivalent groups of patients. A single laboratory comparison of eight kits was undertaken ${ }^{22}$ on 84 dyspeptic patients and compared with histology and UBT. The results showed that all the kits had comparable sensitivity (90-100\%) but more variable and lower specificity (76$96 \%$ ). Indeterminate (grey zone) results occurred with some kits in up to $12 \%$ of the readings, although Premier HP, Pyloriset EIA-G, and HelicoG were calibrated so as not to give grey zone results (the latest version of the last of these kits, HelicoG2, however, does not have a grey zone range). The kit giving the highest percentage of grey zone results was GAP IgG. In this study Pylori ELISA II and Premier HP were particulary effective.

A multilaboratory comparison of eight kits ${ }^{23}$ also showed that all the kits tested were broadly comparable. Some laboratories experienced difficulties with some kits and some kits showed high inter-laboratory variation. Overall the Pyloriset EIA-G and Roche MTP kits seemed to be the best. Again most of the kits produced some indeterminate results but this varied between kits (Roche, 0.9\%; Hel-p Test, 13\%). Table 3 gives the published sensitivity, specificity, positive, and negative values of these kits. 
Table 3 Comparison of commercially available ELISA kits for detection of Helicobacter pylori infection

\begin{tabular}{lllll}
\hline Kit & Sensitivity (\%) & Specificity (\%) & $P P V(\%)$ & $N P V(\%)$ \\
\hline Helori-test & $98-99$ & 88 & 94 & 88 \\
Pyloristat & $91-99$ & $70-94$ & 80 & 84 \\
Pylori ELISA II & 100 & 96 & 97 & 100 \\
Helico G & $71-97$ & $65-95$ & $89-90$ & $65-98$ \\
Helico C 2 & 85 & 76 & 74 & 87 \\
Premier HP & $85-100$ & $80-100$ & $76-100$ & $88-100$ \\
Cobas Core & $87-98$ & $83-98$ & 87 & 86 \\
Pyloriset & $81-97$ & $69-97$ & $76-97$ & $51-98$ \\
Pyloriset update & 100 & 79 & 95 & 100 \\
Hel-p Test & $89-100$ & $62-93$ & $65-90$ & $91-100$ \\
Malakit & $79-87$ & $86-98$ & 96 & 60 \\
GAP IgG & $76-100$ & $26-99$ & $76-100$ & $71-100$ \\
HP kit Radim & 81 & 90 & & \\
Roche MTP & $94-98$ & $83-86$ & 86 & 90 \\
HpG screen & $83-93$ & $68-91$ & $66-84$ & $84-100$ \\
Microstar & 97 & 76 & 80 & 98 \\
SIA Sigma & $85-90$ & $80-98$ & $76-96$ & $88-100$ \\
HM Sigma EIA & $83-98$ & $80-96$ & 76 & 86 \\
Autozyme & 89 & 52 & 58 & 87 \\
Pyloragen & 79 & 75 & 71 & 83 \\
Enzygnost & 80 & 74 & 70 & 83 \\
Quidel EIA & 89 & 66 & 68 & 89 \\
Enzywell & 90 & 71 & 71 & 91 \\
Color Vue & 88 & 86 & 63 & 87 \\
\hline Data taken fran & & & &
\end{tabular}

Data taken from references $12-23,36,37$.

$\mathrm{PPV}$, positive predictive value; NPV, negative predictive value.

\section{Latex agglutination kits}

The agglutination format is not as frequently used as the ELISA format and there have been fewer published evaluations. ${ }^{24-30}$ Pyloriset Dry has replaced Pyloriset LA; it differs in the test procedure, but both use latex beads coated with an acid-glycine extract of $H$ pylori. Both tests detect IgM, IgA, and IgG. The latex agglutination test is more convenient than the ELISA format for near patient testing and has comparable sensitivity and specificity with the ELISA tests (table 4).

\section{Near patient testing}

There is a perceived unmet clinical need for near patient testing of patients for $H$ pylori infection, and several companies have developed rapid tests. Most of the tests consist of one step using whole blood, but others require serum separation, which diminishes their usefulness as near patient kits. With one test kit, variation in sensibility and specificity were noted depending on whether capillary or venous blood was used. Comparatively few assessments have been published. ${ }^{31}{ }^{32}$ The Helisal rapid blood test (Helisal RBT, now superseded by Helisal One Step) had a sensitivity and specificity of 88 and $91 \%$ and a positive predictive value and negative predictive value of 92 and $86 \%$ when compared with histology, culture, RUT, and UBT in 154 dyspeptic patients. ${ }^{33}$ These results compared with 93 and $87 \%$ sensitivity and specificity respec-

Table 4 Comparison of commercially available near patient tests for the detection of Helicobacter pylori infection

\begin{tabular}{lllll}
\hline Kit & Sensitivity (\%) & Specificity (\%) & PPV (\%) & NPV (\%) \\
\hline Helisal RBT & $82-89$ & $55-91$ & 56 & 89 \\
FlexSure HP & $76-96$ & $77-95$ & $72-96$ & $83-95$ \\
Quick Vue & $88-89$ & $70-79$ & $70-82$ & $86-88$ \\
Pyloriset LA & $68-92$ & $56-76$ & $68-85$ & $62-84$ \\
Pyloriset Dry & $64-97$ & $75-95$ & $72-95$ & $75-93$ \\
Quadratech & 83 & 57 & 60 & 81 \\
CLOser & 95 & 72 & 80 & 93 \\
\hline
\end{tabular}

Data taken from references 24-37.

PPV, positive predictive value; NPV, negative predictive value. tively for an ELISA test (HelicoG) in 109 of the patients. Another assessment on 203 patients $^{34}$ compared with RUT/histology gave a sensitivity and specificity of 82 and $91 \%$, and in this study there was concurrence of results whether venous or capillary blood was used. When Helisal was compared with a laboratory ELISA, its sensitivity and specificity were 83 and $78 \%$ respectively. ${ }^{35}$ Other studies have found much lower specificity (55\%) when compared with RUT/histology/culture ${ }^{3637}$ (table 4). Inter- and intra-laboratory comparisons have not yet been performed and published for these kits, but a recent publication does not support the use of these kits as presently formulated for near patient testing. ${ }^{38}$

\section{EFFECT OF POPULATION ON SEROLOGICAL}

RESULTS

Most assessments have been made in adults who were dyspeptic or asymptomatic. It is recognised from sero-epidemiological studies that different ethnic populations have widely differing prevalences of infection and that the assay cut-off value may have to vary to reflect this. Similarly the positive and negative predictive values of the various serological tests may vary according to age, drug administration, or coexistent disease in the population or individual under investigation. Studies in a group of children and in the elderly have shown decreased specificity of the serological tests when compared with culture and histology. ${ }^{39}$ In the elderly this can often be due to atrophic gastritis and reduction in colonisation by $H$ pylori. Apart from this age related effect on the accuracy of serological tests, the use of non-steroid anti-inflammatory drugs ${ }^{40}$ can also affect the test accuracy, as can coexistent disease such as HIV infection, ${ }^{41}$ cystic fibrosis, ${ }^{42}$ and cirrhosis. $^{43}$

SEROLOGY IN DIAGNOSIS AND SCREENING

Serology can only give evidence of contact with $H$ pylori and does not necessarily indicate a current infection. This is more accurately diagnosed using a UBT. Serology, however, like the UBT, is a global test and is not affected by sampling errors, as are the biopsy based tests. In a study comparing all the diagnostic methods available, serology had a sensitivity and specificity of 98 and $95 \%$ respectively compared with 98 and 100\% (culture), 96 and 100\% (PCR), 98 and 98\% (histology), 90 and 100\% (RUT), and 100 and $100 \%\left({ }^{13} \mathrm{C}-\mathrm{UBT}\right),{ }^{44}$ although lower values for the sensitivity and specificity have been obtained in other studies. For example, comparing serology with RUT, sensitivities of 74 and $90 \%$ and specificities of 89 and $96 \%$ respectively were obtained in one study ${ }^{45}$ and sensitivities and specificities of 96 and $88 \%$ for serology were obtained in another study when compared with UBT (96 and 100\%), RUT (92 and $92 \%$ ), and histology (96 and $91 \%){ }^{46}$ The relative sensitivity and specificity of serology obtained in another study, when compared with other diagnostic methods, depended on the population studied, the number of individuals investigated, and the type of serological assay 
used. Serological assays for $H$ pylori infection may have value in both diagnosis and screening and to monitor the effect of eradication treatment. The decision to use one test rather than another depends on the clinical circumstances, the reported test parameters (sensitivity, specificity, positive predictive value, and negative predictive value), cost, and convenience.

There are several possible management algorithms: to treat empirically; to use a screening test and either treat or proceed to endoscopy on the basis of the results; to examine every symptomatic patient by endoscopy. As the latter is an expensive option, various screening strategies have evolved to decrease the number of endoscopies performed. Other factors that need to be taken into account in a management algorithm are age (if over 45 years the patient should proceed to endoscopy without necessarily having a serological test), use of non-steroid anti-inflammatory drugs, and worrying symptoms. Several studies have shown that screening dyspeptic patients using serological tests can be cost-effective in reducing the endoscopy workload by up to $30 \%$ without missing significant pathology. ${ }^{47}{ }^{48}$ Patients who are positive on serological testing can then go on to endoscopy to verify the presence of PUD and hence be started on treatment, or may proceed directly to treatment. However, other studies have shown that if a screening strategy is adopted, significant pathology in some populations can be missed, ${ }^{49}$ and we do not recommend it as a routine practice.

An alternative screening strategy is the use of a symptom questionnaire, and these have been reported to save a similar percentage of endoscopies as serological screening. In one direct comparison of symptom questionnaires with serological screening in 315 patients, ${ }^{50}$ the latter detected more PUD than the questionnaires, but one of the questionnaires was more cost-effective in avoiding unneeded endoscopies. In addition, a cost analysis ${ }^{51}$ of adopting a screening protocol using serological tests compared with empirical treatment with $\mathrm{H}_{2}$ receptor antagonists or an eradication protocol showed that, although the eradication regimen was cheaper than suppressive treatment with $\mathrm{H}_{2}$ receptor antagonists, this was offset by the cost of screening to such an extent that savings were only achieved after eight years. In children, the most cost-effective approach was empirical antisecretory treatment; however, the cost benefit of screening or empirical treatment when compared with direct endoscopy was diminished if the relative costs of endoscopy were low or the recurrence rate of symptoms was high $(>65 \%) .^{52}$ Another cost-benefit analysis ${ }^{53}$ showed that the efficacy of serological testing as a screening procedure depended on a response rate of more than $10 \%$ in non-ulcer dyspepsia (NUD) to eradication of $\mathrm{H}$ pylori, a saving of more than $\$ 4000$ for ulcer prevention and a prevalence rate of more than $10 \%$ of PUD in all dyspeptic patients. Other studies have shown that serological testing can be useful in screening long term dyspeptic patients on suppressive $\mathrm{H}_{2}$ receptor antagonists in a general practice setting. In one practice of 7100 patients, 17 were confirmed as $H$ pylori positive by serology and given an eradication protocol. Four months after successful eradication (confirmed by a UBT), $76 \%$ of the patients were symptom free. ${ }^{54}$ Obviously these percentages may fall with prolonged follow up of the patient.

In addition to screening as a means of reducing the cost of managing dyspepsia, there may be a place for population screening for $H$ pylori infection as a means of preventing gastric cancer. Epidemiological evidence suggests that $31-87 \%$ of gastric cancers may be attributable to colonisation by $H$ pylori, ${ }^{55}$ and it is feasible that eradicating $H$ pylori from an asymptomatic population may reduce the occurrence of gastric cancer. Such interventional studies are underway, but it will be years before any accurate conclusions can be drawn. It is preferable to substantiate the reversibility of premalignant conditions such as atrophic gastritis and intestinal metaplasia after successful eradication of $H$ pylori before wholesale screening is adopted. However, a cost-benefit analysis ${ }^{56}$ showed that, if $30 \%$ of gastric cancers were preventable by a screening eradication protocol, the costeffectiveness was $\$ 25000$ per year of life saved, and this value was approximately maintained even if the success was only $5 \%$ if undertaken in high risk groups.

SEROLOGICAL TESTS FOR THE ASSESSMENT OF ERADICATION OF H PYLORI

After successful eradication of $H$ pylori, antibody levels fall slowly over several months. In one study of 144 patients given eradication treatment, the IgG titre had fallen by $30 \%$ by six weeks after eradication and continued to fall over the succeeding nine months. ${ }^{57}$ Similar reductions in IgG have been found in other studies, ${ }^{58}$ and, although this can be used to assess successful eradication, it is not as convenient as the UBT.

The length of time required to carry out the serological tests mitigates against their use for assessing the success of therapy, as most patients and doctors would prefer to have a more speedy answer, if available. However, the merits of a relatively delayed serological result compared with a more speedy result from the UBT have not been assessed.

SEROLOGICAL MARKERS OF PATHOGENICITY

The high prevalence of $H$ pylori infection throughout the world compared with the relatively low prevalence of the gastroduodenal diseases linked with the infection raises the question of whether all $H$ pylori have the same clinical impact. It has been shown that some genes (vacA, $\operatorname{cag} A, i c e A$ ) confer different biological properties, such as proinflammatory, cytotoxic, and vacuolating activity, which could enhance the in vivo pathogenicity of the bacteria. ${ }^{59}$ CagA and VacA are the most studied of their gene products and are reported to be linked with the more serious diseases. Knowledge of the CagA and VacA status of $H$ pylori infection could be relevant for treatment and for prevention of the possible complications of 
Table 5 Reactivity against Helicobacter pylori lysate, CagA and VacA by RIBA-SIA

\begin{tabular}{llll}
\hline & \multicolumn{2}{l}{ Reactivity (\%) } \\
\cline { 2 - 4 } & Lysate positive & CagA positive & VacA positive \\
\hline Blood donor $(\mathrm{n}=999)$ & 42 & 32 & 15 \\
Non-ulcer dyspepsia $(\mathrm{n}=571)$ & 42 & 36 & 17 \\
Duodenal ulcer $(\mathrm{n}=275)$ & 82 & 70 & 38 \\
Gastric ulcer $(\mathrm{n}=71)$ & 77 & 68 & 38 \\
Gastric cancer $(\mathrm{n}=570)$ & 78 & 61 & 33 \\
Extragastric cancer $(\mathrm{n}=438)$ & 63 & 38 & 21 \\
\hline
\end{tabular}

infection. It is therefore important to diagnose the type of infecting organism. This is serologically possible since CagA protein is highly immunogenic: in fact, more than $95 \%$ of subjects infected by cag $A$ positive $H$ pylori strains develop a serologically detectable response to the gene product (anti-CagA), compared with $0 \%$ of uninfected patients. ${ }^{60}$ However, both the structure of the VacA proteins and the serological response to it are only just being clarified and data are still scanty. These and other as yet undiscovered proteins could therefore lead to the identification of "bad", "very bad", "neutral", or even "good" H pylori strains, as recently speculated by Blaser. ${ }^{61}$ The serological techniques currently available to determine the cytotoxic type of infecting strains are western blotting and ELISA. A novel recombinant immunoblott assay (RIBASIA; Chiron Corp., Emeryville, California, USA) has recently been proposed which contains individual bands for whole $H$ pylori lysate, recombinant $\mathrm{CagA}$, and VacA. In a recent evaluation of anti-CagA and anti-VacA reactivity by RIBA-SIA in large populations of both asymptomatic subjects and patients with different pathologies, anti-CagA mainly but also anti-VacA reactivities were found to be more prevalent in patients with severe gastroduodenal pathology (table 5).$^{62}$ Similarly the seroprevalence of anti-CagA reactivity assessed by ELISA (Helori-CTX; Eurospital, Trieste, Italy) was confirmed as being higher in $\mathrm{H}$ pylori positive subjects with gastric or duodenal ulcer than asymptomatic subjects or patients with NUD. ${ }^{63}$ The results of a large multicentre study carried out in Italy involving over 3000 patients examined by endoscopy in more than 90 endoscopy units have recently been published. ${ }^{64}$ CagA prevalence was assessed by ELISA in this large population, and the preliminary results in over 1300 patients confirm the association between CagA and major gastroduodenal pathology (table 6).

Many similar, although smaller, studies have previously shown the association between CagA as a marker for PUD and gastric cancer, ${ }^{6566}$ although other studies have not found this association. ${ }^{67}$
MARKERS OF GASTRIC INFLAMMATION AND $H$ PYLORI

To distinguish PUD (in which the eradication of $H$ pylori is recommended) from NUD (in which the role of $H$ pylori is controversial), it is necessary to perform an endoscopy. Neither serological tests nor UBT give any quantitative information that would help to differentiate between these two conditions. ${ }^{68}$ However, measurement of blood markers of gastric inflammation may give some clinical information that is useful in the management of $H$ pylori related disease.

\section{Gastrin}

$H$ pylori infection is associated with a set of well recognised disturbances to normal gastric physiology. Plasma gastrin levels are elevated in $H$ pylori infection $(150 \mathrm{ng} / \mathrm{ml})$ compared with control levels $(50 \mathrm{ng} / \mathrm{ml}$ ) as a consequence of inhibition of somatostatin production. After eradication of $H$ pylori the plasma gastrin levels return to normal.

Higher levels of plasma gastrin are found in corpus gastritis than in antral gastritis, ${ }^{69}$ but there is no significant difference between the levels in gastritis compared with ulceration. ${ }^{70}$

\section{Pepsinogen}

Variations in concentrations of pepsinogen (PG) I and II and the PGI:II ratio can occur with age, weight, smoking, and chronic renal failure. Increases in both PGI (73 ng/ml compared with $50 \mathrm{ng} / \mathrm{ml}$ ) and PGII $(24 \mathrm{ng} / \mathrm{ml}$ compared with $10 \mathrm{ng} / \mathrm{ml}$ ) with a reduction in the PGI:II ratio (3.6 compared to 6.2) are found in $H$ pylori associated gastritis compared with $H$ pylori negative individuals. ${ }^{71}$ Some studies have shown that PGI levels are even further elevated in $H$ pylori associated PUD compared with those without PUD, ${ }^{72}$ and the elevation correlates with the degree of inflammation. A high PGI:II ratio is found in ulceration associated with the Zollinger-Ellison syndrome. In $H$ pylori associated gastritis the increase in PGI is least in corpus only gastritis and highest in predominantly antral gastritis. Reduction in both PGI and PGII and normalisation of the ratio can be used to confirm successful eradication of $H$ pylori, ${ }^{73}$ although a decrease in PGII is the most accurate biomarker of eradication compared with PGI, serology, and serum gastrin. ${ }^{75}$

Variation in the levels and ratio of PG can be used to predict the presence of more serious gastric pathology. Used as a screening test in an asymptomatic population, a low PGI combined with $H$ pylori positivity can predict gastric atrophy with a sensitivity and specificity of 88 and $92 \%$ respectively. ${ }^{76} \mathrm{~A}$ high serum IgA anti- $H$ pylori antibody level associated with a

Table 6 Prevalence of CagA by ELISA in Helicobacter pylori positive patients according to endoscopic findings

\begin{tabular}{lllllll}
\hline & Normal & Gastritis duodenitis & Gastric ulcer & Duodenal ulcer & Gastric cancer & Overall \\
\hline CagA $^{+}$ & $117(55.7)$ & $322(59.6)$ & $41(80.4)$ & $171(85.1)$ & $6(85.7)$ & $671(64.7)$ \\
CagA $^{-}$ & $93(44.3)$ & $219(40.5)$ & $10(19.6)$ & $30(14.9)$ & $1(14.3)$ & $366(35.3)$ \\
Overall & $210(20.2)$ & $541(39.3)$ & $51(4.9)$ & $201(19.4)$ & $7(0.7)$ & $1037(100)$ \\
\hline
\end{tabular}

Values in parentheses are percentages. 
decreased PGI ( $<50 \mathrm{ng} / \mathrm{ml})$ correlates with an increased risk of gastric cancer, with an odds ratio of 5.95 in one study population. ${ }^{77}$

Conversely there is an inverse correlation between serum IgG anti-H pylori antibody levels and the extent of gastric metaplasia, but only in those individuals that have normal PGI levels. ${ }^{78}$ Screening strategies have been developed to detect gastric adenocarcinoma using a combination of $H$ pylori positivity and PG and gastrin levels. ${ }^{79} 80 \mathrm{~A}$ study of 686 patients, of which 150 had gastric adenocarcinoma, showed that age above 62 years, low PGI levels, low PGI $\times$ gastrin value, and low PGI:gastrin ratio were indicative of gastric adenocarcinoma, with the value of serum PGI being the most important.

\section{Conclusions}

The exact role of serological testing in the management of $H$ pylori infection is yet to be defined. However, used as a screening procedure, it can reduce endoscopy workload and cost, although the savings may take several years to accumulate.

Used in conjuction with blood levels of gastrin and PGs, these tests can suggest the presence of $H$ pylori associated gastritis and be used to screen for serious gastroduodenal pathology, although further work is required to clarify their usefulness in this aspect.

The role of $H$ pylori in NUD will affect how these blood tests are used in the management of Helicobacter infections. Currently, eradication of $H$ pylori is only recommended in cases of PUD, and endoscopy is required to differentiate PUD from NUD. Therefore blood tests that could achieve this differentiation may reduce the endoscopy workload even further.

Italian Helicobacter pylori Study Group

Project leaders: D Vaira, M Miglioli, L Barbara (First Medical Clinic, University of Bologna).

Study co-ordinators: V Alvisi (GI Unit, University of Ferrara, Emilia Romagna); P F Bajeli (GI Unit, University of Siena, Toscana); G Bianchi Porro (GI Unit, Sacco Hospital, Milano, Lombardia); F Di Mario, M Plebani (GI Unit and Biochemestry, University of Padova, Veneto e Friuli Venezia Giulia); G Dobrilla (GI Unit, Bolzano, Trentino Alto Adige); A Francavilla (GI Unit, University of Bari, Puglia/Basilicata); G Gasbarrini (First Medical Clinic, University of Roma, Lazio); G Mazzacca (GI Unit, University of Napoli, Campania); M Neri (Dept of Internal Medicin, University of Chieti Abruzzo/Marche/ Molise); F Pallone (GI Unit, University of Catanzaro Calabria); A Ponzetto (GI Unit, S G Battista Hospital, Torino Piemonte/ Liguria/Val d'Aosta); G Realdi (1st Medical Clinic, University of Sassari Sardegna); S Vigneri (Department of Internal Medicine, University of Palermo Sicilia). The following centres participated (number of enrolled
subjects): Abruzzo/Marche/Molise: R Bernabei, L Lombardi, M subjects): Abruzzo/Marche/Molise: R Bernabei, L Lombardi, M A Pistoia, Cattedra di Endoscopia and Laboratorio Analisi, Divisione di Gastroenterologia, Università L'Aquila (29); F Divisione di Gastroenterologia, Universita L'Aquila (29); F Cipollini, Divisione di Gastroenterologia, Ospedale di Ascoli Università di Chieti (35); A Angelone, F Cifani, S Di Matteo, Divisione di Gastroenterologia and Anatomia Patologica, Ospedale di Pescara (35); G Carota, L De Feudis, O Pesa, Divisione di Medicina Interna, Ospedale di Penne (40 lost); D Susi, Divisione di Gastroenterologia, Ospedale di Termoli (39); C De Fanis, G Sciampa, A Spadaccini, Divisione di Gastroenterologia, Ospedale di Vasto (39). Calabria: M Imeneo, F Luzza, M Maletta, Cattedra di Gastroenterologia, Policlinico Mater Domini Università di Reggio Calabria, Catanzaro (37); A De Medici, A Giglio, E Valentini, Divisione di Gastroenterologia and Laboratorio Analisi, Ospedale Ciaccio, Catanzaro (37); E Ciliberto, C Labate, G Panuccio, Divisione di Gastroenterologia, Ospedale SGiovanni di Dio, Crotone (21); A Lauria, A gia, Ospedale SGiovanni di Dio, Crotone (21); A Lauria, A Luvera, F Polimeni, Divisione di Gastroenterologia, Ospedale E tini, W Taccone, Divisione di Gastroenterologia, Ospedale SG Moscati, Avellino (38); G Claar, L Santoro, Divisione di
Gastroenterologia, Ospedale G Moscati Aversa (18); G Forte, E Grimaldi, P Rocco, Divisione di Gastroenterologia, Ospedale Civile di Caserta (32); P Avagliano, V Baldi, G Cotugno, Divisione di Gastroenterologia, Ospedale S Maria dell'Olmo, Cava dei Tirreni, Salerno (28); F Castiglione, A Sarubbi, Cattedra Di Gastroenterologia, Università di Napoli (36); B De Luca, L De Luca, P Di Giorgio, Divisione di Gastroenterologia, Ospedale Vecchio Pellegrini, Napoli (27); M A Bianco, L Cipolletta, P Russo, Divisione di Gastroenterologia, Ospedale Maresca Torre del Greco, Napoli (35). Emilia Romagna: P Azzarone, M Menegatti, C Ricci, I Clinica Medica, Università di Bologna (36); V Modugno, V Salicini, Divisione di Gastroenterologia and Laboratorio Analisi, Ospedale Militare di Bologna (23); C Rubbiani, E Zirilli, Divisione di Gastroenterologia and Laboratorio E Zirilli, Divisione di Gastroenterologia and Laboratorio Analisi, Ospedale Ramazzini di Carpi (27); A P Cipolloni, P
Fabbri, G Gentili, Divisione di Gastroenterologia and LaboraFabbri, G Gentili, Divisione di Gastroenterologia and Labora-
torio Analisi, Ospedale M Bufalini, Cesena (37); G Marangoni, torio Analisi, Ospedale M Bufalini, Cesena (37); G Marangoni,
M Ruina, W Balhous, Cattedra di Gastroenterologia, Università di Ferrara (46); A Casadei, P Maiolo, S Pignatari, Medicina di Ferrara (46); A Casadei, P Maiolo, S Pignatari, Medicina G De Frabitiis, Divisione di Gastroenterologia and Laboratorio Analisi, Ospedale di Imola (40); E Cristofori, G Rani, C Staffa, Divisione di Gastroenterologia and Laboratorio Analisi, Ospedale di Lugo (38); G Bedogni, G Bertoni, R Sassatelli, Servizio di Endoscopia Digestiva, Ospedale S Maria Nuova, Reggio Emilia (36); A Cardelli, S Gasperoni, Divisione di Gastroenterologia,Ospedale degli Infermi, Rimini (18). Lazio: S D'Addesa, I De Vitis, V Festa, Clinica Medica I, Policlinico Gemelli, Università di Roma (40); L M D'Anna, G Giumbo, D Annibali, Servizio di Endoscopia Digestiva Policlinico Militare Roma (29). Lombardia: G Drago, F Negrini, S Signorelli, DiviRoma (29). Lombardia: G Drago, F Negrini, S Signorelli, Divisione di Gastroenterologia and Laboratorio Analisi, Ospedali
Riuniti, Bergamo (37); G Bianchi, A M Fasani, P Politi, Riuniti, Bergamo (37); G Bianchi, A M Fasani, P Politi,
Divisione di Gastroenterologia and Laboratorio Analisi, OsDivisione di Gastroenterologia and Laboratorio Analisi, Os-
pedale di Cremona (38); R Ceruti, F Ferrarini, S Guanella, Divisione di Gastroenterologia, Laboratorio Analisi ed Anatomia Patologica, Ospedale C Poma Mantova (18); M Lazzaroni, O Sangaletti, Divisione di Gastroenterologia, Ospedale Sacco, Milano (39); A R Baldassarri, P Bianchi, M Quattrini, Patologia Medica, Università di Milano (36); A Grossi, R Gusmaroli, F Milesi, Divisione di Gastroenterologia and Laboratorio Analisi, Ospedale di Treviglio, Treviglio, Bergamo (55); L Cattani, E Colombo, P A Testoni, Divisione di Gastroenterologia, Policlinico S Marco, Zingonia Bergamo (36). Piemonte/Ligurial Valle D'Aosta: S Boscarino, A Vanni, R Vanni, Divisione di Medicina Interna, Ospedale S Spirito, Bra, Cuneo (23); M Bongera, S Peyre, B Treves, Laboratorio Analisi and Divisione di Gastroenterologia, Ospedale Civile di Cuorgne', Cuorgne', Torino (44); G Clerico, P V Galetto, Divisione di Gastroentero-
logia, Ospedale Civile, Ivrea, Torino (26); C Manini, E Seglie, D Stramignoni, Reparto di Chirurgia, Anatomia Patologica, Ospedale Civile S Croce, Moncalieri, Torino (38); M Colozza, B F Sallio, R Suriani, Laboratorio Analisi e Divisione di Gastroenterologia, Ospedale degli Infermi, Rivoli, Torino (36); E Fanciulli, F Minetti, Divisione di Medicina and Laboratorio Analisi, Ospedale S Paolo, Savona (39); A Morgando, C Perotto, G Pugliese, Dipartimento di Gastroenterologia, Ospedale S G Battista, Molinette, Torino (38); R Ferraris, C Marini, S Taraglio, Divisione di Gastroenterologia, Laboratorio Analisi and Anatomia Patologica, Ospedale Mauriziano Umberto I, Medicina Generale e Laboratorio Analisi, Ospedale S Andrea, Medicina Generale e Laboratorio Analisi, Ospedale S Andrea,
Vercelli (35). Puglia/Basilicata: A Ferraioli, G Fregola, R Milano, Vercelli (35). Puglia/Basilicata: A Ferraioli, G Fregola, R Milano, pedale Miulli Acquaviva delle Fonti, Bari (39); E Ierardi, M pedale Miulli Acquaviva delle Fonti, Bari (39); E Ierardi, M Ingrosso, M Margiotta, Cattedra di Gastroenterologia, Universita di Bari (40); C Leoci, A Di Leo, G Di Matteo, Divisione di Gastroenterologia e Laboratorio di Biochimica, Ospedale De
Bellis Castellana Grotte, Bari (39); R Antonetti, D Faleo, P Frigerio, Divisione di Gastroenterologia and Laboratorio Analisi, Ospedali Riuniti Foggia (20); B Andriulo, G Bonanno, $\mathrm{G}$ Santoro, Divisione di Gastroenterologia and Laboratorio Analisi, Ospedale Civile Ostuni, Ostuni, Brindisi (31); A Andriulli, F Perri, G Lauriola, Divisione di Gastroenterologia and Laboratorio Analisi, Ospedale Casa Sollievo Sofferenza, S Giovanni Rotondo, Foggia (36). Sardegna: R Carruxi, L Demelia, F Gervasi, Clinica Medica, Università di Cagliari (28); F Oliviero, F Oppia, MR Piras, Divisione di Gastroenterologia, Ospedale Civile di Cagliari (40); L Cugia M P Dore, Clinica Medica Civile di Cagliari (40); L Cugia, M P Dore, Clinica Medica, niversita di Sassari (35); G Dettori, A Niolu, G Noya, Clinica Chirurgica, Università di Sassari (40); G Sanna, M Spanedda, M Meloni, A Sanna, Divisione di Medicina Interna II, Ospedale Civile di Sassari (40). Sicilia: G Branciforte, F Catalano, R CatCivile di Sassari (40). Sicilia: G Branciforte, F Catalano, R Catanzaro, Istituto di Medicina Interna, Università di Catania (45);

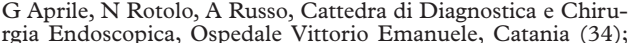
AR Castellino, D Abate, G Meli, Divisione di Medicina Interna and Laboratorio Analisi, Ospedale S Giacomo, Licata, Agrigento (12); A Bertino, M Bottari, G Di Pasquale, Cattedra di Diagnostica e Chirurgia Endoscopica and Laboratorio Analisi, Università di Messina (19); A D'Angelo, S La Chiusa, L Montalbano, Medicina Interna and Laboratorio Analisi, Ospedale Buccheri La Ferla, Palermo (18); M Marino, R M Provenzani, G Reina, Servizio di Endoscopia and Laboratorio Analisi, Ospedale Villa Sofia, Palermo (20); N Fontana, R Termini, Istituto Di Medicina Interna e Geriatria, Universita' di Palermo (37); S Peralta, E Piccione, A Proclamà, PatologiaMedica Uni(28); A Marino, C Di Franco, F Di Trapani年, Divisione di Gastroenterologia, Ospedale Civico Benfratelli, Malermo (39); G Gatto, A Rizzo, N Salamone, Divisione di Palermo (50); M Evola, V Zagardo, Divisione di Gastroenterologia, Ospedale M Chiello, Piazza Armerina, Enna (23); 
L Nicoletti, G Scarpulla, I Tallo, Divisione di Gastroenterologia and Laboratorio Analisi, Ospedale Raimondi, S Cataldo, Caltanissetta (42). Toscana: A Calabrò, G Macri', G Salvadori, Cattedra di Gastroenterologia, Università di Firenze (38); E Mei, D Panconi, G A Rinaldi, Divisione di Gastroenterologia and Laboratorio Analisi, Ospedale di Lucca (38); F Costa, G Maltinti, S Marchi, Cattedra di Gastroenterologia, Università di Pisa (37); M Lombardi, R Rossetti, E Torelli, Divisione di Gastroenterologia and Laboratorio Analisi, Pistoia (40); C Basagni, N Figura, Patologia Medica, Università di Siena (38). Trentino alto Adige: S Amplatz, L Piazzi A Lang, Divisione di Gastroenterologia and Laboratorio Analisi, Ospedale Generale Regionale Bolzano (36); A Mayr, P Santer, H Steiner, Divisione di Medicina Interna and Laboratorio Analisi, Ospedale di Brunico, Brunico, Bolzano (20); A Bernardi, S Gottardi, A Meggio, Divisione di Gastroenterologia, Ospedale di Rovereto, Rovereto, Trento (37); F De Berardinis, G Maistri, Divisione di Gastroenterologia and Laboratorio Analisi, Ospedale S Chiara, Trento (40). Veneto/Friuli Venezia Giulia: M T Camagna, F Costan, N Papa Anatomia Patologica, Divisione di Gastroenterolotan, N Papa Anatomia Patologica, Divisione di Gastroenterologia and Laboratorio Analisi, Ospedale di Belluno (37); G Farisano R Marin, E Nisi Laboratorio Analisi, Divisione di Gastroenterologia and Anatomia Patologica, Ospedale Dolo,
Dolo, Venezia (38); G Dalla Corte, M De Boni, C Doglioni, Laboratorio Analisi, Divisione di Gastroenterologia and AnatoLaboratorio Analisi, Divisione di Gastroenterologia and Anato-
mia Patologica,, Ospedale di Feltre, Feltre, Belluno (62); E Benedetti, F Komauli, C Rizzi, Divisione di Gastroenterologia, Anatomia Patologica, and Laboratorio Analisi, Ospedale Civile di Gorizia (38); D Causarano, S Grassi, Divisione di Medicina Interna, Ospedale di Marostica, Marostica, Vicenza (63); M Caroli, O Del Maschio, A Saggioro, Divisione di Gastroenterologia and Anatomia Patologica, Ospedale Umberto I Venezia, Mestre (33); R Barbazza, A Conti, A Cosentino, Anatomia Patologica, Divisione di Gastroenterologia and Laboratorio A Farruggio, G Maschio, Divisione di Gastroenterologia, Anatomia Patologica, and Laboratorio Analisi, Ospedale di Montagnana, Montagnana, Padova (14); M Rugge, Anatomia Montagnana, Montagnana, Padova (14); M Rugge, Anatomia
Patologica, Università di Padova (38); M Milan, A Palleschi, A Patologica, Università di Padova (38); M Milan, A Palleschi, A P Rimondi, Divisione di Gastroenterologia, Laboratorio Analisi and Anatomia Patologica, Ospedale di Rovigo (26); N Bizzaro A Girardi, G Sacchi, Laboratorio Analisi, Divisione di Gastroenterologia and Anatomia Patologica, Ospedale Civile S Dona' Di
Piave, Venezia (37); C Monti Bragadin, M Frezza, C Widmaier, Piave, Venezia (37); C Monti Bragadin, M Frezza, C Widmaier, Laboratorio Analisi and Divisione di Gastroenterologia, Ospedale di Cattinara, Strada di Fiume, Trieste (40); G Bulighin, G Guidi, O Ruzzenente, Divisione di Gastroenterologia and Laboratorio Analisi, Università di Verona, Valeggio sul Mincio, Verona (30); G Battaglia, M Bergamasco, M Pasquino, Divisione di Gastroenterologia and Laboratorio Analisi, Presidio Ospedaliero Venezia (34); M Franceschi, A Pilotto, M Scagnelli, Divisione di Medicina Interna and Microbiologia, Ospedale Civile S Bortolo, Vicenza (36); L Bittesini, V Boni, O Ca Bianca, Anatomia Patologia, Divisione di Gastroenterologia and Laboratorio Analisi, Ospedale di Vittorio Veneto, Treviso (36).

Referral histopathology: G Biasco, M Renga (First Medical Referral histopathology: G B

Orinic, University of Bologna). Organisation staff: M Caradonna (Diagnostic Division,
Eurospital, Trieste, Italy), F Landi, A Ali' (First Medical Clinic,

Eniversity of Bologna).

Epidemiology and statistical evaluation: D Palli, C Saiev
F Cimoli (Epidemiology Unit, CSPO, AO Careggi, Firenze).

1 Von Wuiffen H, Grote HJ. Enzyme linked immunosorbent assay for the detection of $\mathrm{IgA}$ and $\mathrm{IgG}$ antibodies to C. assay for the detection of IgA and IgG antibodies
pylori. Eur f Clin Microbiol Infect Dis 1988;7:559-65.

2 Hirschl AM, Pletschette M, Hirschl MH, et al. Comparison of different antigen preparations in an evaluation of the immune response to C. pylori. Eur f Clin Microbiol Infect Dis 1988:7:570-5.

3 Talley NJ, Newell DG, Ormand JE, et al. Serodiagnosis of $\mathrm{H}$. pylori: comparison of enzyme linked immunosorben assays. F Clin Microbiol 1991;29:1635-9.

4 Stacey AR, Hawtin PR, Newell DG. Antigenicity of fractions of $\mathrm{H}$. pylori prepared by fast protein liquid chromatography and urease captured by monoclonal antibody. Eur f Clin Microbiol lnfect Dis 1990;9:732-7.

5 Gerstenecker B, Eschweiler B, Vogele H, et al. Serodiagnosis of $\mathrm{H}$ pylori infections with an enzyme immunoassay using the chromatographically purified 120 kilodalton protein. Eur f Clin Microbiol lnfect Dis 1992;11:595-601.

6 Newell DG, Johnston BJ, Ali MH, et al. An enzyme-linked immunosorbent assay for the serodiagnosis of Campyloimmunosorbent assay for the serodiagnosis of Campylobacter pylori-associate
(suppl) 1988;142:53-7.

7 Bolton FJ, Hutchinson DN. Evalutation of three Campylobacter pylori antigen preparations for screening sera from patients undergoing endoscopy. F Clin Pathol 1989;42:7236

8 Hirschl AM, Rathbone BJ, Wyatt J, et al Comparison of ELISA antigen preparation alone or in combination for
serodiagnosing Helicobacter pylori infection. $\mathcal{F}$ Clin Pathol 1990;43:511-13.

9 Pateraki E, Mentis A, Spilladis C, et al. Seroepidemiology of Immunol 1990;2:129-36.

10 Xiao SD, Pan ZJ, Zhang ZH, et al. Enzyme-linked immunosorbent assay for detection of immunoglobulin G antibody
against Helicobacter pylori. Chin Med $\mathcal{F}$ (Engl) 1991;106: against

11 Xiang Z, Bugnoli M, Ponzetto A, et al. Detection in an enzyme immunoassay of an immune response to a recom- binant fragment of the 128 kilodalton protein (CagA) of Helicobacter pylori. Eur f Clin Microbiol Infect Dis 1993;12:

12 van den Over HL, Loffeld RJ, Stobberingh EE. Usefulness of a new serological test (Bio-Rad) to diagnose Helicobacter pylori associated gastritis. F Clin Microbiol 1991;29: 283-6.

3 Goossens H, Glupczynski Y, Buretto A, et al. Evaluation of a commercially available complement fixation test for diagnosis of Helicobacter pylori infection and for follow-up after antimicrobial therapy. F Clin Microbiol 1992;30:32303.

14 Aguirre PM, Pascual CY, Merino FJ, et al. Evaluation of two commercial enzyme immunoassays for the diagnosis of 1992;11:684-9.

15 Trautmann $M$, Moldrzyk M, Vbogt $\mathrm{K}$, et al. Use of a receiver operating characteristic in the evaluation of two commercial enzyme immunoassays for detection of Helicobacter pylori infection. Eur F Clin Microbiol Infect Dis 1994; 136:2-8.

16 Granberg C, Mansikka A, Lehtenen OP, et al. Diagnosis of Helicobacter pylori infection by using pyloriset EIA-G and EIA for detections of serum immunoglobulin $G(\operatorname{IgG})$ and IgA antibodies. F Clin Microbiol 1993;31:1450-3.

17 Raymond J, Kalach N, Bergeret M, et al. Evaluation of a serological test for a diagnosis of Helicobacter pylori infection in children. Eur f Clin Microbiol Infect Dis 1996;15: $415-17$

18 Marchildon PA, Ciota LM, Zamaiyan FZ, et al. Evaluation of three commercial enzyme immunoassays compared with the ${ }^{13} \mathrm{C}$ urea breath test for detection of Helicob

19 Talley NJ, Kost L, Haddad A, et al. Comparison of commercial serological tests for detection of $\mathrm{H}$ pylori antibodies. $\mathcal{F}$ Clin Microbiol 1992;34:3146-50.

20 Weiss J, Mecca J, daStiva E, et al. Comparison of PCR and other diagnostic techniques for detection of $\mathrm{H}$. pylori infection in dyspeptic patients. 7 Clin Microbiol 1994;32: $94-7$.

21 Van de Wouw BA, de Boer WA, Janez AR, et al. Comparison of three commercially available enzyme linked immunosorbent assays and biopsy dependent diagnosis for detecting H. pylori infection. F Clin Microbiol 1996;4:94-7.

22 Wilcox MH, Dent TH, Hunlet JO, et al. Accuracy of serology for the diagnosis of $\mathrm{H}$. pylori infection: a comparison of eight kits. F Clin Pathol 1996;49:373-6.

23 Feldmann RA, Deeks JJ, Evans SJW et al. Multi-laboratory comparison of eight commercially available $\mathrm{H}$. pylori serology kits. Eur 7 Clin Microbiol Infect Dis 1995;14:428-33.

24 Lozniewski A, de Korwiri JD, Conroy MC, et al. Evaluation of Pyloriset Dry, a new agglutination test for $\mathrm{H}$ pylori antiof Pyloriset Dry, a new agglutination test for H pylor
body detection. F Clin Microbiol 1996;34:1773-5.

25 Hirschl AM, Hirschl MM, Berger J, et al. Evaluation of a commercial latex test for the serological diagnosis of $\mathrm{H}$. pylori infection in treated and untreated patients. Eur F Clin Microbiol Infect Dis 1991;10:971-4.

26 Hoek FJ, Noach LA, Rauws AJ, et al. Evaluation of the performance of commercial kits for detection of $\mathrm{H}$ pylori antibodies in serum. F Clin Microbiol 1992;30:1525-8.

27 Jensen AKV, Andersen LP, Wachmann CH. Evaluation of eight commercial kits for $\mathrm{H}$. pylori IgG antibody detection. APMIS 1993;101:795-801.

28 Midolo PD, Lambert JR, Russel FG, et al. A practical single sample dry latex agglutination test for $\mathrm{H}$. pylori antibody detection. 7 Clin Path 1995;48:969-71.

29 Schembri MA, Lin SK, Lambert JR. Comparison of commercial diagnostic tests for $\mathrm{H}$. pylori antibodies. $\mathcal{F}$ Clin Microbiol 1993;31:2621-4.

30 Westblom TU, Madan E, Gudipatt S, et al. Diagnosis of $\mathrm{H}$. pylori infection in adults and pediatric patients by using Pyloriset, a rapid latex agglutination test. $\mathcal{F}$ Clin Microbiol 1992;30:96-8.

1 Graham DY, Evans DJ, Peacock J, et al. Comparison of rapid serological tests (FlexsureHP and Quick Vue) with conventional ELISA for detection of $\mathrm{H}$. pylori infection. $A m \mathcal{F}$ Gastroenterol 1996;91:942-7.

32 Chen TS, Chang FY, Lee SD. Serodiagnosis of H. pylori infection: comparison and correlation between enzyme linked immunosorbent assay and rapid serological test results. F Clin Microbiol 1997;35:184-6.

33 Moayyedi P, Carter AM, Catto A, et al. Validation of a rapid whole blood test for diagnosing $\mathrm{H}$. pylori infection. $B M \mathcal{F}$ 1997;314:119.

34 Borody TJ, Andrews P, Shortis NF. Evaluation of whole blood antibody kit to active H. pylori infection. Am $\mathcal{f}$ Gastronterol 1996;91:2509-12.

35 Jones R, Phillips I, Felix G, et al. An evaluation of near patient testing for $\mathrm{H}$. pylori in general practice. Aliment Pharmacol Ther 1997;11:101-5.

36 Stevens M, Livsey SA. MDA Evaluation Reports No 41, 43, $44,48,58,60,63,64,65,74,82,85,89$. Norwich: HMSO, 1996.

37 Stevens M, Livsey SA. MDA Evaluation Reports No 15, 16, 17, 37, 43. Norwich: HMSO, 1997.

38 Anon J. Helicobacter pylori testing kits. Drugs and Therapeutics Bulletin 1997;35:23-4.

39 Raymond J, Kalach N, Bergered M, et al. Evaluation of serological test for diagnosis of $\mathrm{H}$ pylori infection in children. Eur f Clin Microbiol Infect Dis 1996;15:415-17.

40 Taha AS, Reid J, Boothmann P, et al. Serological diagnosis of $\mathrm{H}$. pylori: evaluation of four tests in the presence or absence of non-steroidal anti-inflammatory drugs. Gut
1993;34:461-5. 
41 Fabbris $\mathrm{P}$, Bozzola L, Benedetti $\mathrm{P}$, et al. $\mathrm{H}$ pylori infection in HIV positive patients. A serological study. Dig Dis $S c i$ HIV positive patie
1997;42:289-92.

42 Johansen HK, Norgaard A, Andersen LP, et al Cross reactive antigens shared by Ps Aeruginosa, $\mathrm{H}$ pylori, $\mathrm{C}$ jejuni and Haem influenzae may cause false positive titres of antibody to H. pylori. Clin Diag Lab Immunol 1995;2:149-55.

43 Nardone G, Coscione P, D'Armiento FP, et al. Cirrhosis negatively affects the efficency of serological diagnosis of $\mathrm{H}$. pylori infection. Ital f Gastroenterol 1996;28:332-6.

44 Thijs JC, Vanzwet AA, Thijs WJ, et al. Diagnostic tests for H. pylori: a prospective evaluation of their accuracy Gastroenterol 1996;91:2125-9.

45 Faigel DO, Childs M, Furth EE, et al. New non invasive test for Helicobacter pylori gastritis. Comparison with tissuebased gold standard. Dig Dis Sci 1996;41:740-8.

46 Lin SK, Lambert JR, Schembri M, et al. A comparison of diagnostic tests to determine Helicobacter pylori infection. diagnostic tests to determine Helicobact

47 Mendall MA, Goggin PM, Marrere JM, et al. Helicobacter pylori screening prior to endoscopy. Eur $\mathcal{f}$ Gastroenterol Hepatol 1992;4:713-17.

48 Patel P, Khulus S, Mendall MA, et al. Prospective screening of dyspeptic patients by $\mathrm{H}$. pylori serology. Lancet 1995;346:1315-18

49 Denis P, De Koster E, Nyst JF, et al. H. pylori serology as a screening method prior to upper gastrointestinal endoscopy in young dyspeptic patients. a different point of view. Acta Gastroenterol Belg 1995;58:378-81.

50 Mendall MA, Jazrawi RP, Marrero JM, et al. Serology for $\mathrm{H}$ pylori compared with symptom questionnaires in screening before direct access endoscopy. Gut 1995;36:330-3.

51 Briggs AH, Sculpher MJ, Logan RP, et al. Cost effectiveness of screening and eradication of $\mathrm{H}$. pylori in management of dyspeptic patients under 45 years of age. $B M \mathcal{F} 1996 ; 312$ 1321-5.

52 Olson AD, Fendrik AM, Deutach D, et al. Evaluation of initial non-invasive therapy in paediatric patients presenting
with suspected ulcer disease. Gastrointest Endosc 1996;44: 554-61.

53 Sonnenberg A. Cost benefit analysis of testing for H. pylori in dyspeptic subjects. Am 7 Gastroenterol 1996;91:1773-7.

54 Rosengren $\mathrm{H}$, Polson RJ. The role of screening for $\mathrm{H}$. pylor in patients with duodenal ulceration in the primary health care setting. Br f Gen Pract 1996;46:177-9.

55 Forman D. The prevalence of Helicobacter pylori infection in gastric cancer. Alimen Pharmacol Ther 1995;9(suppl 2):71-6.

56 Parsonnet J, Harris RA, Hack HM, et al. Modelling cost effectiveness of $\mathrm{H}$. pylori screening to prevent gastric cancer: a mandate for clinical trials. Lancet 1996;348:1504.

57 Kosunen TM, Seppala K, Sama S, et al. Diagnostic value of decreasing IgG, IgA and IgM antibody titres after eradication of H. pylori. Lancet 1992;339:893-5.

58 Kosunen TU. Antibody titres in H. pylori infection: implications in the follow-up of antimicrobial therapy. Ann Med 1995;27:605-7.

59 Censini S, Lange C, Xiang Z, et al. CagA pathogenicity island of Helicobacter pylori encodes type I-specific and disease-associated virulence factors. Proc Natl Acad Sci USA 1996;93:14648-55.

60 Cover TL, Glupczynski Y, Lage AP, et al. Serologic detection of infection with CagA+ Helicobacter pylor strains. F Clin Microbiol 1995;33:1496-1500.

61 Blaser MJ. Not all helicobacter pylori strains are created equal: should all be eliminated? Lancet 1997;349:1020-2.
62 Vaira D, Menegatti M, Fusconi M, et al. Helicobacter pylori: detection of anti-Lysate, -CagA and -VacA reactivity by . subjects [abstract]. Gut 1997,41:A163.

63 Vaira D, Menegatti M, Farinelli S, et al. Determination of anti-CagA reactivity by an ELISA assay in different populations [abstract]. Gut 1997;41:A161.

64 Palli D, Vaira D, Menegatti M, et al. A serologic survey of Helicobacter pylori infection in 3281 Italian patients endoscoped for upper gastrointestinal symptoms. Aliment Pharmacol Ther 1997;11:719-28.

65 Parsonnet J, Friedman GD, Orantreigh N, et al. Risk for gastric cancer in people with CagA positive or CagA negative Helicobacter pylori infection. Gut 1997;40:297-301.

66 Peek RM Jr, Miller GG, Tham KT, et al. Heightened inflammatory response and cytokine expression in vivo to CagA positive Helicobacter pylori strains. Lab Invest 1995; 73:760-70.

67 Pan ZJ, Vander Hulst RW, Felter $M$, et al. Equally high prevalences of infection with CagA positive Helicobacter pylori in Chinese patients with peptical ulcer disease and those with chronic gastritis-associated dyspepsia. I Clin Microbiol 1997;35:1344-7.

68 Sharma TK, Prasad VM, Gutter AF. Quantitative noninvasive testing for $\mathrm{H}$ pylori does not predict gastroduodenal disease. Gastrointest Endosc 1996;44:679-82.

69 Karttunen T, Niemals S, Lehola J. H. pylori in dyspeptic patients: quantitative association with severity of gastritis, intragastric pH and serum gastrin conc

70 Elomar E, Penmar I, Dorrian CA, et al. Eradicating H. pylori infection lowers gastrin mediated acid secretion by two thirds in patients with duodenal ulcer. Gut 1993;34: $1060-5$.

71 Veenendaal RA, Biomond I, Pena AS, et al. Inflence of $\mathrm{H}$. pylori infection on serum pepsinogen in healthy blood transfusion donors. Gut 1992;33:452-5.

72 Biasco G, Paganelli GM, Vaira D, et al. Serum pepsinogen I and II concentration and IgG antibody to $H$. pylori in dysand II concentration and IgG antibody to $\mathrm{H}$.

73 Park SM, Park J, Jang SK, et al. H. pylori infection and serum pepsinogen I concentration in peptic ulcer patients: effect of bacterial eradication. Korean fournal of Medicine 996;13:1-8.

74 Hunter FM, Correa P, Fontham E, et al. Serum pepsinogen as markers of response to therapy to H. pylori gastritis. Dig Dis Sci 1993;38:2081-6.

75 Plebani M, Basso D, Scrigner M, et al. Serum pepsinogen C a useful marker of $\mathrm{H}$. pylori eradication? fournal of Clinical Laboratory Science 1996;10:1-6.

76 Knight T, Wyatt J, Wilson A, et al. H. pylori gastritis and serum pepsinogen levels in a healthy population: development of a biomarker strategy for gastric atrophy in a high risk group. Br f Cancer 1996;73:419-24.

77 Aromaa A, Kosunen TU, Kneki P, et al. Circulating anti $\mathrm{H}$. pylori immunoglobulin $\mathrm{A}$ antibodies and low serum pepsinogen I levels are associated with increased risk of gastric cancer. Am f Epidemiol 1996;144:142-9.

78 Osawa H, Inoue F, Yoshida Y. Inverse relationship of serum $\mathrm{H}$ pylori antibody titre and extent of intestinal metaplasia.

79 Lin J, Lee WC, Wu MS, et al. Diagnosis of gastric adenocarcinoma using a scoring system: combined assay of serological marker of $\mathrm{H}$ pylori infection, pepsinogen I and gastrin. f Gastroenterol 1995;30:156-61.

80 Wu MS, Lee WC, Lin JT, et al. A novel tree-structured analysis for non-invasive diagnosis of gastric adenocarcinoma. Anticancer Res 1995;15:2739-45. 